\title{
Systematic synthesis and multi-criteria evaluation of transmission topologies for electric vehicles
}

\author{
Sven Köller ${ }^{1}\left[\right.$ - Vincent Schmitz ${ }^{1}[$
}

Received: 5 July 2021 / Accepted: 30 November 2021 / Published online: 20 December 2021

(C) The Author(s) 2021

\begin{abstract}
The focus on the expansion of the electrification of vehicles becomes stronger. Thus, the development process of powertrains of those cars needs to be more dynamic to react to the new challenges. One way to accelerate the development is to automate predevelopment and evaluation at an early stage. An automated method to synthesize transmission topologies and pre-design gears for the generated topologies for electric vehicles is presented within this paper. The method contains two internal evaluations - one after the topology synthesis and the second after the initial design of the gears. The results of the method are gear ratios and gear data for the single transmission steps of each topology. The inputs and boundary conditions can be easily changed and fitted to specific requirements for all use-cases. Here, the process is explained, and the methods' results are validated using state-of-the-art passenger vehicle transmission. As for electric trucks, no state-of-the-art electric powertrains exist; the method is subsequently applied to find topologies for a heavy-duty truck. Extracts of the results are presented. The application for trucks is carried out within the publicly funded research project "Concept ELV". In general, the method is capable of synthesizing transmissions for any given vehicle and motor combination.
\end{abstract}

Keywords Integrated transmission design $\cdot$ Automated synthesis $\cdot$ Evaluation $\cdot$ Electric vehicles $\cdot$ E-Mobility $\cdot$ Virtual development methods

\section{Introduction}

The United Nations agreed on reducing greenhouse emissions significantly within the Paris Agreement [27]. A main factor in achieving the goals of the agreement is to reduce emissions in road transport. In the European Union (EU), reducing greenhouse emissions is stated in different regulations for passenger cars and trucks [6-8]. One possible way to reduce emissions efficiently are electric cars and trucks.

Electric cars are already available from different manufactures and across various classes (e.g., BMW i3, VW ID3, Porsche Taycan, Audi eTron, Tesla Model S). The development of electric trucks is not as advanced as in cars. Due to a later start of carbon dioxide regulations for trucks, the

Sven Köller

sven.koeller@ika.rwth-aachen.de

Vincent Schmitz

vincent.schmitz@rwth-aachen.de

1 Institute for Automotive Engineering (Ika), RWTH Aachen University, Aachen, Germany manufacturers started electrifying trucks later. Further reasons are the high requirements for electric trucks. Logistic companies expect the same additional loading weight as for a conventional truck. This is hard to realize as the battery for an electric truck is heavy and may reduce the loading weight. Additionally, cost pressure is high, and like electric cars, electric trucks will have higher initial costs. The first prototypes and small series by manufacturers such as Daimler Truck AG, MAN and DAF are available to the customers today and already have been tested in small prototype series.

Transmission topologies used in electric vehicles (EV) differ significantly from conventional drives with an internal combustion engine (ICE). BMW uses a two-stage, singlespeed, spur-gear transmission in the i3, whereas Porsche and Audi apply combinations of spur and planetary gears in the Taycan and eTron [1, 2, 24]. Also, various transmission topologies emerge within the truck segment-even if there is little data available today (see, e.g., [28]. The majority of the manufacturers did not publish their concepts in detail to the public yet.

New development approaches gain importance to identify all possible, well-suited solutions within the wide array of 
new concepts. A further aspect of developing new transmissions with an electric drive is a reduction in iterations within the design process to save costs and accelerate the development process. This is important as the market is very dynamic due to fast improvements in the technology sector of electrified vehicles which is underlined by a growing number of different EVs in the market. Additionally, highly efficient transmissions become more critical as the range of an EV is directly dependant on drivetrain efficiency, and customers demand high ranges in an EV comparable to those of conventional ICE vehicles (see, e.g., [19]).

One possibility to conquer the challenges described are automated transmission syntheses, which may integrate evaluations of their solutions based on preliminary parameters and designs. This process can support engineers in a very early development stage by finding possible solutions and giving a holistic overview of the solution space. The following section gives a short overview of transmission synthesis approaches in different use-cases.

\section{Overview of transmission synthesis approaches}

Different synthesis approaches for transmissions integrate different parts of the design process. Some take a defined topology and synthesize, e.g., the best gearing design. Others take a set of boundary conditions and synthesize the best transmission topology, or the synthesis focuses on finding an optimal powertrain topology. All approaches have the aim to support engineers in choosing the best fitting solution within their application in common. In the following sections, a short overview of relevant research on syntheses is presented.

The approach to automatically synthesising transmissions with computer resources is not new, e.g., Xingyuan Li already presented a method to synthesize planetary transmissions in 1993. This method uses the stationary ratio and the number of clutches and brakes as boundary conditions. Different filters are used to sort out unsuitable solutions after all theoretically possible solutions were generated in the first step. Unsuitable solutions are, e.g., those which have an improper static ratio [17].

A more recent contribution to transmission syntheses by Hirzel deals with the realization of a good speed distribution for electrified, hybrid vehicles. The focus is on evaluating all possible gear distributions. These are examined and analyzed, e.g., regarding their shift ability. Combinations of spur and planetary gear sets are considered. The main purpose of this work is to synthesize transmissions with several speeds for hybrid cars to integrate the electric machine as well as the ICE. The possible structures are analysed regarding, among others, installation space, deviation to the required ratio and losses in the transmission. As the stadium of the development is an early one, only gearing losses can be considered. The method is exemplarily applied to design an eight-speed hybrid transmission [9].

Lin Li also introduces a transmission synthesis for powertrains of hybrid vehicles. In this research, a so-called baseline structure is used as the base, e.g., two planetary gear sets. The process starts with adding couplings between single gear sets of the baseline structure and propulsion inputs. The method consists of several steps with increasing complexity. First, only topologies with one input, one output and a single-speed are considered. This is followed by adding shift elements to synthesize a three-speed transmission based on the initial results. In the next step of the synthesis, two electric machines are added to the synthesized transmissions to realize the hybrid functions. Finally, the transmissions are evaluated regarding their feasibility and kinematics. The remaining concepts are evaluated towards the driving mode and coverage of the vehicle demand map within a separate simulation. Next to the restrictions from the baseline structures, the stationary ratios of the planetary gear sets are also specified and fixed. The number of possible transmissions grows to more than 120 billion solutions reduced to 10,000 after the kinematics and feasibility check. At the end of the driving mode evaluation, only 235 feasible topologies are left. No statement concerning the computational time is made. The transmissions are described mathematically [18].

Silvas presents an approach aiming to find a powertrain topology of hybrid vehicles rated by costs and functionality. So, this work does not focus on transmissions directly. Nevertheless, it is important to be listed here as it generally contains important ideas towards syntheses, e.g., libraries for different parts of the powertrain (gear sets, clutches, power electronics). The components are combined holistically. Also, the different possibilities to connect a planetary gear set are considered in the evaluation. The more components are given into the method, the longer the computational time becomes. The solving algorithm is based on constraint programming. For the used example case, a computational time of 5 minutes is stated [26].

Another concept of a synthesis approach for hybrid powertrains is realized by Ruoff. Within this research, a component library is defined as a basis for the method. Like Silvas, powertrain topologies are the main focus, but all six connection possibilities of planetary gear sets are evaluated. The description of the generated topologies is done mathematically. The solutions are saved as matrices. All concepts are evaluated by an automatic rating process-focusing on propulsion system properties as energy consumption and performance. The properties of the evaluation can be given different weights due to the application field of the vehicle. The rating's results are shown as a utility. The method is 
verified using a state-of-the-art hybrid powertrain of a passenger vehicle. For this example, a period of "one day" is stated to get more than 100 rated topologies [25].

One example of an available commercial transmission synthesis tool is Mahle ZG's Plangear. This tool uses a two-stage process. First, kinematics of the possible gearsets are determined using a lever model — the relevant levers are defined beforehand. For more detailed information on the use of lever models refer to, e.g., [16]. A particular focus lies in considering complex planetary gear structures. In the next step, other basic conditions like ratios or a maximum number of shifting devices are given. With this information, the length of the levers and the speeds of the parts are synthesized. Furthermore, a shifting matrix is evaluated. After the lever model is completed, planetary gearsets that are equivalent to the previous results can be manually defined from a library. This is followed by an evaluation on gear level, where toothing data are presented. With this information, all speeds and torques in the system are calculated. The main strength of the method is to determine complex planetary gear sets as combined Ravigneaux sets. The evaluation time for a ZF 9HP equivalent transmission is roughly 1 day on a current desktop computer [31].

Lastly, at the Institute for Automotive Engineering (ika) of RWTH Aachen University, an approach for transmission synthesis with an integrated evaluation specifically focused on electric vehicle transmissions is developed. The synthesis approach consists of a holistic combination of transmission stages into transmissions. This is followed by analytically designed toothing geometries of the stages. An evolutionary algorithm combines these results to find the best solution (the terms evolutionary and genetic algorithm are used interchangeably in this publication). Internal evaluations complement the process to get a tangible result [15]. Additionally to the synthesis, a chosen transmission topology can be optimized. That includes, e.g., an automated design of the shaft-bearing system and a rough housing draft [13]. The next chapters will describe the method of the transmission synthesis in detail, followed by validation using a transmission that is available on the market and the application within a truck transmission.

\section{Methodology/conception of transmissions}

Based on the previously presented approaches, the ika transmission synthesis process for electric vehicles has been developed. The novel aspect of this synthesis is that the holistic synthesis of topologies is followed by an optimized initial gear design for every topology variant. The considerable portion of the development process automated by this methodology is a novel aspect of this publication. The focus is not solely finding an optimal topology or optimizing an existing one but the combination of both: finding all feasible topologies with an optimized design and evaluating the best fit for the application within a good computing time.

The methodology can be applied to any type of vehicle with defined electric motor(s) to synthesize all feasible transmission topologies. The following figure shows the process of the method within a flowchart. The method is divided into three main steps (see Fig. 1): 1: topology synthesis, 2: initial dimensioning and 3: evolutionary design combination.

After the first and last step, the variants are automatically evaluated. The topology synthesis produces every transmission topology which is suited to fulfil driving requirements for the specified vehicle motor combination. It also includes the first evaluation, where an initial structuring of topologies is performed by rough estimations of characteristic criteria. The output of this first step is a ranked list of all possible transmission topologies. The initial gear dimensioning step contains an analytical design process based on ISO 21771 and ISO $6336[11,12]$. It is used to generate a large number of geometry variants with sufficient load capacity. In the final step, an optimized subset of geometry variant combinations is identified using an evolutionary algorithm. The evaluation in the evolutionary combination step ranks the geometry variants for each topology according to their precise geometric and load-bearing criteria.

The three stages of the methodology and corresponding evaluations are illustrated in detail in the following chapters. The whole process is executed automatically after entering the initial parameters - though it can be stopped at intermediate steps to evaluate interim results manually or to choose only specific results for the further process by hand. The user
Fig. 1 Flowchart of presented transmission synthesis method

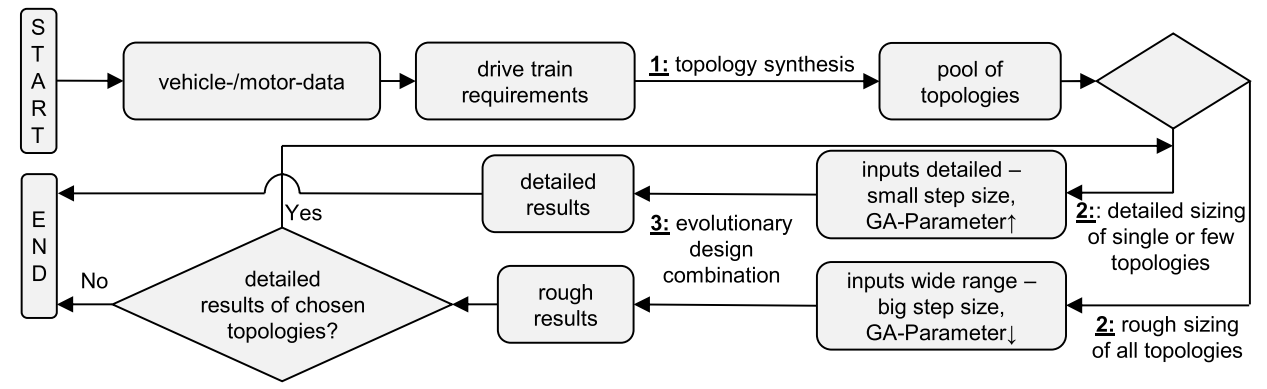


can define different weights for the criteria in both evaluation steps to focus the optimization on particular aspects of the transmission (e.g., mass, efficiency or lifetime). All functions are implemented as program code in MATLAB. So, the applicant has many freedoms to adapt the method to its requirements.

\subsection{Topology synthesis and initial evaluation}

The topology synthesis starts by providing the method with information about vehicle and motor(s). The vehicle inputs mainly consist of parameters for the analytic calculation of driving resistances and requirements for maximum acceleration, speed and climbing ability. The motor parameters contain nominal and maximum speeds and torques as well as speed ranges for optimal efficiency and maximum power. The process of this part of the method is shown in Fig. 2.

In the first step of the synthesis, the total gear ratio and the number of speeds are calculated-derived from the driving requirements and the specifications of the electric machine. Maximum speed or climbing ability dictates the gear ratio of the first gear. It is then determined whether top speed requires a different gear ratio, i.e., if the transmission needs more than one speed. Additionally, a ratio for driving at a good efficiency can be considered. For this, the most driven speed of the vehicle and the speed-torque point with the highest efficiency of the e-machine is used. The aim is to get a ratio that enables to meet the best efficiency of the e-machine at the longest possible timeslot in the defined use case of the vehicle-for a long-haul truck, it should be around $80 \mathrm{~km} / \mathrm{h}$. The formulas from the transmission design for ICE drivetrains are used to get the required torques at the wheel resulting from driving resistances at defined load points [21]. As current electric vehicles mostly have one or two speeds, the following steps will evaluate transmissions

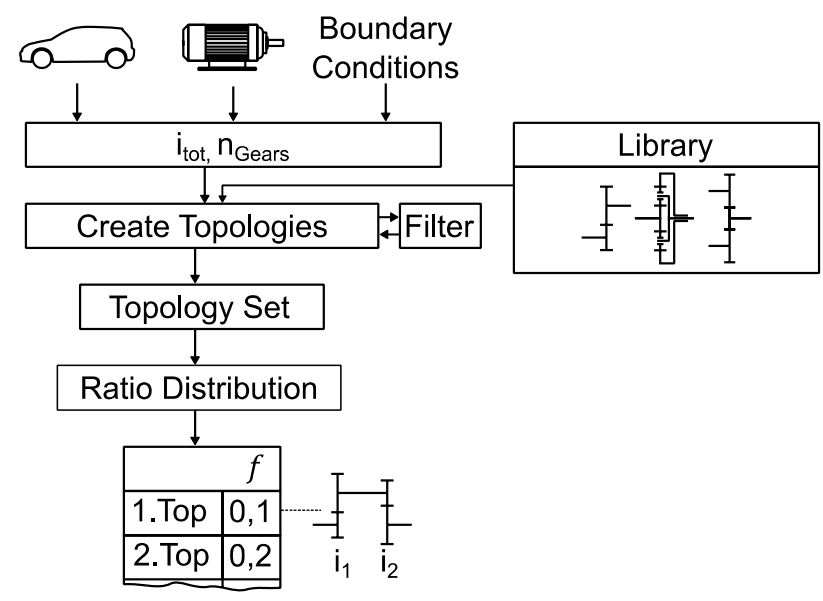

Fig. 2 Topology synthesis process (tot: total; Top: Topology) within these boundaries of a maximum of two speeds. (cf. $[3,5,23,30])$.

The second step generates all possible topology variants by combining stage types from a library into transmissions. As of today, the library contains spur, planetary and superimposing gears which are used to join two separate powertrain parts into one. They consist of two pinions driving a shared gear. Differentials are modelled as the spur gears on their cage, as they do not have an internal gear ratio. Every stage type in the library also has a minimum and maximum allowed gear ratio based on literature values. The method iterates every possible combination of the stage elements up to a predefined maximum number of stages. The results are filtered for feasibility during the iteration by checking for the required total gear ratio and a matching number of inputs/ outputs of subsequent stages. The final result of this methodology step is the set of topologies that are theoretically feasible using the base elements of stages from the library.

For the further design of the topology variants, the total gear ratio has to be distributed between the stages of the topologies. That requires an evaluation method to determine which gear ratio distributions and, subsequently, topologies are more favourable than others. The method uses the "requirement-oriented, weighted evaluation with sharply defined numbers" for this purpose [4]. This evaluation method defines criteria and associated weights for the evaluation of technical systems.

These criteria are estimated based on the stage gear ratios and stage types of the topology variants. They are modelled for spur, planetary and superimposing gears based on values taken from literature as follows. The results are used for an initial evaluation of the topologies. The estimations are relatively crude due to little available data at this early point in the development process. Nonetheless, they are still suited to distribute the stage gear ratios and rank the topology variants into an initial order. The variants will be re-evaluated in the evolutionary design combination when calculated and more detailed data is available. The criteria of the synthesis, listed in Table 1, is explained in the following paragraphs.

Gearset complexity is one of the simplest criteria. It is modelled by the number of major individual parts in the gear stages (gears, synchronizers, clutches and brakes). The more individual parts a gear stage possesses, the more complex it is (see Table 2). Spur and planetary gear stages are modelled

Table 1 Evaluation criteria in the topology synthesis 
Table 2 Estimation of complexity criterion for spur, planetary and superimposing gear stages (1 and 2-speed)

\begin{tabular}{lll}
\hline No. indiv. parts & 1-speed & 2-speed \\
\hline Spur gear & 2 & 5 \\
Planetary gear & 5 & 7 \\
Superimposing gear & 3 & - \\
\hline
\end{tabular}

as one- and two-speed, while the superimposing gear is only considered with one speed. The one-speed versions of the gear types only count the number of gears. Two-speed spur gears gain two additional gears and a synchronizer (No. indiv. parts +3 ), while two-speed planetary gears gain one clutch and one brake (No. indiv. parts +2 ). Two-speed planetary gear sets are modelled as either running as a block with a ratio equal to one or shifted with a ratio bigger than one. The overall complexity of a single topology is computed from the sum of individual parts. For example, an one-speed transmission topology consisting of two spur gear stages has a complexity $C=4$.

Gearset costs are roughly estimated using data presented by [14]. This work provides an initial estimation for relative costs and masses of spur and planetary gears as a function of their gear ratios (Fig. 3). These estimations are used to determine a relative cost value $k(i)$ for the different gear types. As the used models only intend to roughly consider the costs connected to their ratio, this model is detailed enough to compare spur- and planetary gears in a first step. And by this, at least approximately include cost behaviour in the evaluation.

Costs for two-speed variants and superimposing gears are modelled from Fig. 3 by simple comparison. The costs of two-speed spur gears are assumed as twice the costs of 1 -speed spur gears because twice as many gears are needed. Costs for a two-speed planetary set are assumed to be equal to the one-speed variant because there are no additional gears. Synchronizers, clutches and brakes are neglected. The costs for a superimposing gear are assumed as 1.5 times the costs of a one-speed spur gear because there are three instead of two gears (see Table 3).
Table 3 Cost estimation for spur, planetary and superimposing gears (1 and 2-speed)

\begin{tabular}{lll}
\hline Rel. costs & 1-speed & 2-speed \\
\hline Spur gear & $k_{\mathrm{Sp}}(i)$ & $2 \cdot k_{\mathrm{Sp}}(i)$ \\
Planetary gear & $k_{\mathrm{Pl}}(i)$ & $k_{\mathrm{Pl}}(i)$ \\
Superimposing gear & $\sim 1.5 \bullet k_{\mathrm{Sp}}(i)$ & - \\
\hline
\end{tabular}

Table 4 Mass estimation for spur, planetary and superimposing gears (1 and 2-speed)

\begin{tabular}{lll}
\hline Rel. mass & 1-speed & 2-speed \\
\hline Spur gear & $m_{\mathrm{Sp}}(i)$ & $2 m_{\mathrm{Sp}}(i)$ \\
Planetary gear & $m_{\mathrm{Pl}}(i)$ & $m_{\mathrm{Pl}}(i)$ \\
Superimposing gear & $\sim 1.5 m_{\mathrm{Sp}}(i)$ & - \\
\hline
\end{tabular}

Table 5 Efficiency estimation for spur, planetary and superimposing gears (1- and 2-speed)

\begin{tabular}{lll}
\hline Efficiency & 1-speed & 2-speed \\
\hline Spur gear & 0,99 & 0,99 \\
Planetary gear & 0,9825 & 0,9825 \\
Superimposing gear & 0,99 each mesh & \\
\hline
\end{tabular}

The total costs $K$ for a topology variant are then computed by adding all gear stage costs.

Gear stage masses are estimated analogously to gear stage costs because the same assumptions hold true, as shown in Table 4 . The total mass $M$ of a topology variant is the sum of the individual gear stage masses.

Gear stage efficiencies are estimated using common literature values for the efficiencies of the spur gear and planetary meshes $[21,29]$. For two-speed planetary gears, the state of a ratio bigger than one is always evaluated as this is the lower efficiency (see Table 5). The total topology efficiency is calculated as the product of gear stage efficiencies. Should there be more than one motor, the total efficiency $\eta$ is obtained from the power balance.
Fig. 3 Left: relative cost $(k)$ and right: mass $(m)$ values for spur $(\mathrm{Sp})$ and planetary $(\mathrm{Pl})$ gears as a function of gear ratio $(i)$ (cf. [14])
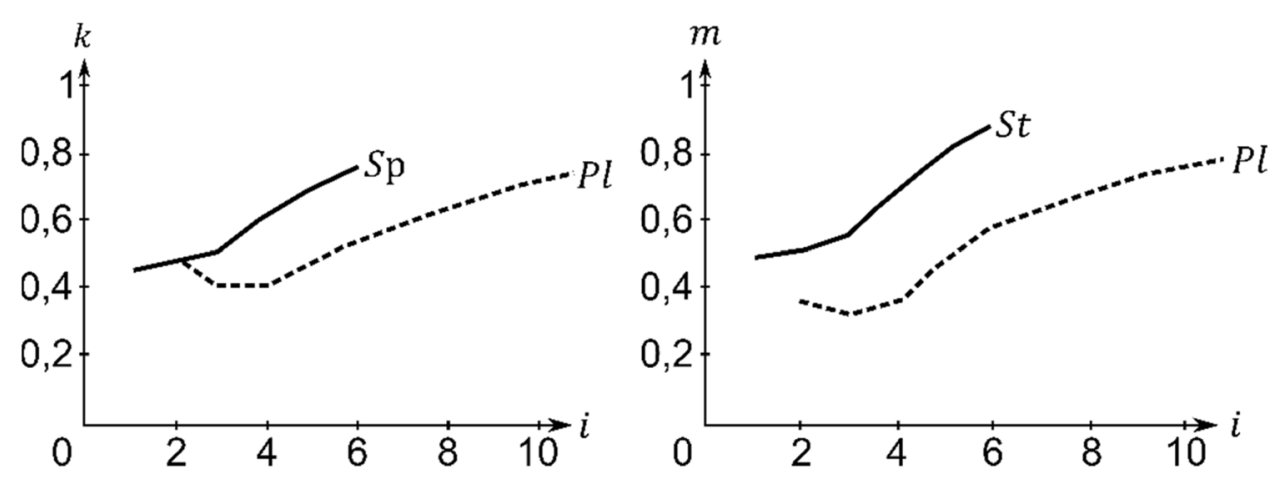
The bearing speed criterion is employed to generate topologies that may employ standard bearings instead of specialized high-speed bearings. Those can be a major cost factor in electric powertrains due to the high speeds of electric motors. Furthermore, the lifetime of bearings depends on the number of rollovers and thus on their speed. The bearing speed of gear stages can be easily calculated from the speed of the driving motor and the gear ratios up to the gear stage, which is currently of interest. The bearing speed $n_{k}$ of the $k$-th gear stage is:

$n_{k}=\frac{n_{\mathrm{mot}}}{\prod_{j=1}^{k} i_{j}}$

To describe a whole topology, the sum of individual gearset speeds, $N$ is used. It is formed by adding the bearing speeds $n_{k}$ of all gear stages $k$. This approach is used to roughly estimate the influence of different ratios and topologies on the bearings which are chosen later in the development process. If the first gear steps ratios are high, high motor speeds are reduced directly, and thus high-speed bearings are more likely unnecessary after one gear step. Standard bearings could be used instead. Bearing loads cannot be considered as they strongly depend on the resulting forces of two gears on a shaft. The design and optimization of bearing loads is part of subsequent steps like [13] presented.

$N=\sum_{k} n_{k}$

All criteria values are subsequently normalized and combined into an overall worth $W$ of a topology variant. The overall worth is defined as the sum of normalized criteria values multiplied with their corresponding weight factors. The user can alter the weight factors to shift focus between the criteria.

$W(i)=g_{c} \cdot C+g_{K} \cdot K(i)+g_{M} \cdot M(i)+g_{\eta} \cdot \eta+g_{N} \cdot N(i)$

Because cost, mass and bearing speed criteria depend on the gear ratio distribution $i$, the overall worth of a topology $W$ is also a function of $i$. The stage gear ratios are distributed by an optimization algorithm, which aims to minimize $W(i)$ by varying $\boldsymbol{i}$. Criteria are reformulated during normalization if necessary to accommodate this optimization goal (e.g., efficiency $\rightarrow$ losses). The result of the optimization is an optimal gear ratio distribution $i^{*}$ for every topology.

$i^{*}$ such that $W\left(i^{*}\right)=\min (W(i))$

The final result of the synthesis step is a list of topologies which are ranked by their overall worths $W$. The gear ratio distribution of every topology is designed to ensure the most desirable values for the evaluation criteria. The created topologies may be plotted automatically in figures like, e.g., Fig. 9.

\subsection{Initial gearset dimensioning}

The second step of the methodology concerns the initial dimensioning of a gear set. This takes either all or only manually chosen topologies that result from the synthesis and splits it into its gear stages. Then, the three different types of gear stages are initially dimensioned by three different design functions (see Fig. 4). These functions execute the gearset design process specified in $[11,12]$, generating a geometry with sufficient load capacity. The user can supply a load collective for this step. The design process in [11, 12] needs certain input parameters (e.g., allowed helix angle range, wheel width range, normal pressure angle range) to generate a gearing geometry. Instead of computing a single geometry from a set of values for the input parameters, the design functions calculate multiple geometry variants from several different values for each input parameter.

The input values are contained in vectors whose upper and lower limits, as well as spacing, can be set by the user. These settings have a strong influence on the variety of geometries the method considers. The user can set narrow bounds with fine spacing to investigate a known geometry in more detail or use wide bounds with bigger spacing to get an initial overview of possible geometries. In every case, the available memory of the computer has to be considered. Because of memory limitations, a strictly holistic approach is unfeasible beyond this point. The solution space has to be restricted by the input vectors; otherwise, a very high number of possible solutions would occur.

The initial dimensioning results are tables for every gear stage of one topology containing all parameters needed to specify a geometry. Each line in the tables represents a

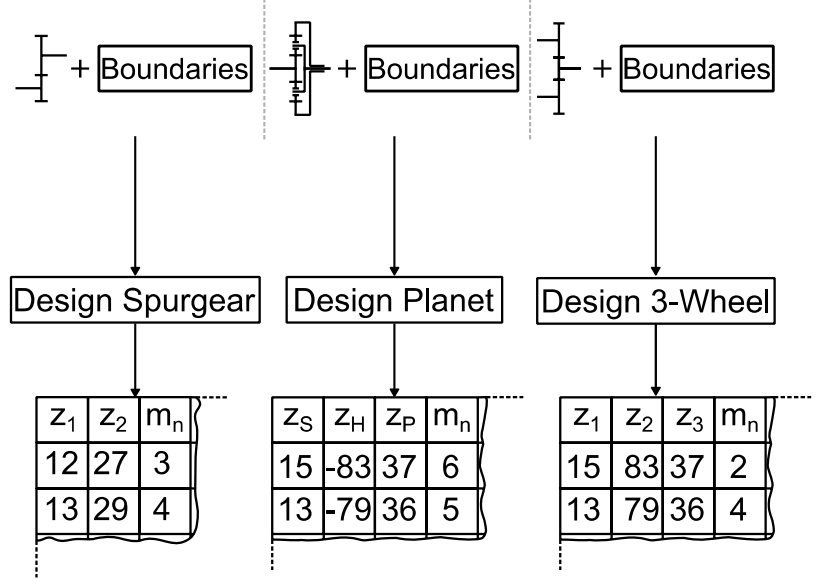

Fig. 4 Initial gearset design process (S: Sun gear; H: Ring gear; P: Planet) 
different geometry variant. Depending on the input vectors, the solution tables may contain up to $10^{7}$ or even more geometry variants-all suitable to fit the requirements. More variations may be possible if the RAM of the used computer is sufficient.

\subsection{Evolutionary design combination and final evaluation}

The final step of the methodology combines the geometry variants from the geometry tables into gear sets (compare Fig. 1). A defined number of gear sets is then optimized using an evolutionary algorithm. During the optimization, a fitness value $F$ (see Formula (5)) is computed for every gear set, and the gear sets evolve to better fitness values. The fitness value represents the final evaluation of the variants, which results in the final fitness ranking. The process to approach the fitness value is shown in Fig. 5 .

First, the method combines gear stage geometries into gear sets by picking lines from the geometry tables of every transmission step. Every combination of lines constitutes a gear set individual. A specified number of individuals forms the initial population of the evolutionary algorithm. Their geometry table lines are picked randomly. For every individual in the population, the fitness value is computed. A defined elite fraction proceeds to the next generation unaltered. The elite fraction contains individuals with top fitness values. The rest is subjected to recombination and mutation, where the geometry line indices are interchanged between two individuals or randomly changed for one. This process is iterated for a set number of generations, which improves the fitness of the individuals and the population as a whole [20]. The fitness function is set so that a good fitness value describes a desirable gear set. The fitness

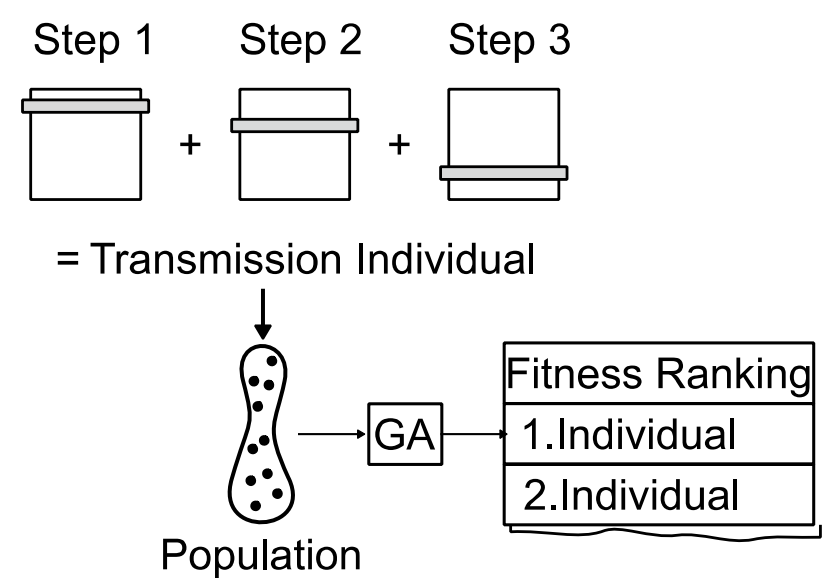

Fig. 5 Evolutionary design combination process (GA: Genetic Algorithm) value is formed from the weighted sum of four criteria shown in Table 6.

The values for these criteria are all obtained from the geometry tables. Especially for mass and efficiency, the estimations from chapter 3.1 are not used any further because the initial gearset design has provided calculated data for these criteria. The mass is now obtained by a cylindric approximation using the dimensions of all gears and the material density. The gearing efficiency is obtained from an analytical calculation developed by [22]. Service life and safety result from the analytical approach of ISO 6336 [11, 12].

Before the fitness value is computed from the criteria, the values extracted from the geometry tables (index $T$ ) are normalized to a common scale from 0 to 10 (Fig. 6). Because service life and safety do not get more desirable with ever-increasing values, they are scaled by a graphsimilar to a parabola-whose optimum is set by the user. The optimum must be between the minimum and maximum value. The position of the optimum for evaluation can be set freely in between. Mass and efficiency are more desirable the lower or respectively higher the value is. These criteria are thus normalized using a linear function. If service life and safety had linear curves, the transmission would become over-dimensioned.

Table 6 Criteria for an evaluation in evolutionary combination

\begin{tabular}{lc}
\hline Criteria design combination & \\
\hline Service life & $L$ \\
Safety & $S$ \\
Mass & $m$ \\
Efficiency & $\eta$ \\
\hline
\end{tabular}
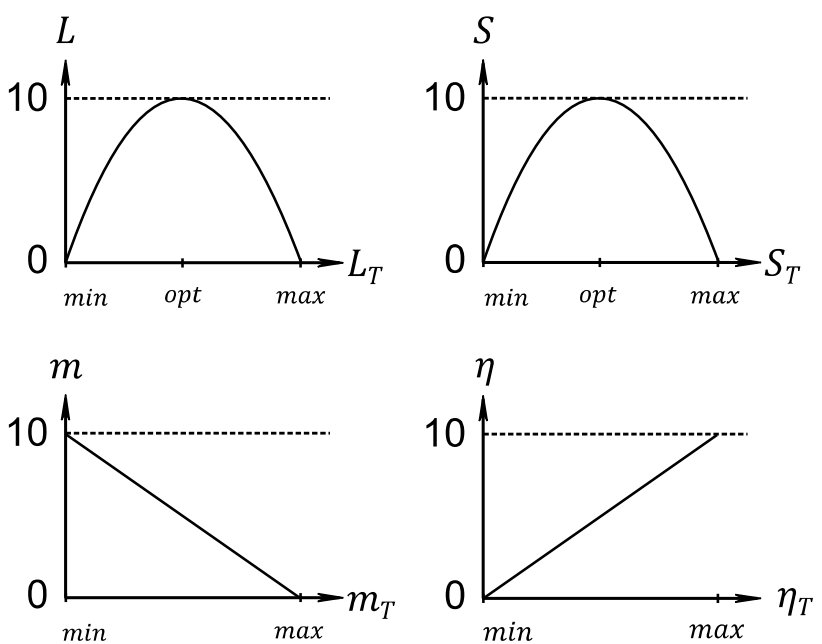

Fig. 6 Normalization of combination criteria from table values (index $T)$ ( $L$ : Service Life; $S$ : Safety; $m$ : mass; $\eta$ : Efficiency) 
After normalization, the fitness score $F$ is computed from the weighted sum of the criteria. As seen before in the synthesis evaluation, the user can set the weights individually to shift focus between the criteria.

$F=g_{L} \cdot L+g_{S} \cdot S+g_{m} \cdot m+g_{\eta} \cdot \eta$

The variants generated by the methodology are structured first by their topology ranking from the synthesis step. Each topology from this ranking consists of an arbitrary number of geometry variants that are also ranked compared to one another. This structured data can be helpful to provide an initial overview for developers or to examine a variety of possible solutions in more detail. Depending on if all possible topologies or only a few specially chosen topologies are considered, the step size of gear parameters (e.g., width, helical angle) in the boundary conditions may be adapted. For a rough overview, a wide range with a bigger step size is used. For a detailed preliminary design, the step size should be small within a smaller range. An approach may be that an overview of all possibilities is generated in the first step, and in the second step, e.g., the best topology is taken to be designed more detailed. The next chapter presents the validation of the results using a passenger vehicle and the application of the method on a truck.

\section{Application of the methodology}

This section concerns the application of the methodology in two separate parts. First, the methodology is applied to a BMW i3 to validate the method by generating a state of the art result. In the second part, the methodology is applied to a 40-ton truck to present the holistic aspect of the approach and the variety of generated results. That is especially interesting in heavy-duty applications where no status quo transmission layout has emerged yet. The design of a transmission for a 40-ton truck is part of the "Concept ELV" "project [10].

The calculations for this study were executed on RWTH Aachen's High Power Computing Cluster (HPC). 16 $2.1 \mathrm{GHz}$ cores with $160 \mathrm{~GB}$ of memory were employed.

Some settings for the genetic algorithm are different for passenger cars and 40-ton trucks because of many more topologies for the truck powertrain. If settings are not equal, first, the cars' setting followed by the trucks are given ( $\mathrm{car}$ / truck). The population for the evolutionary algorithm was set to $10,000 / 2000$ individuals, and the termination condition was set to 1000/300 computed generations. The elite fraction was $5 \%$, while the recombination fraction was $50 \%$. This set of parameters was determined by previous calibration runs, which aimed to combine swift computation time with a satisfactory quality of results.

\subsection{Validation of method's results by BMW i3 transmission}

To apply the method to the BMW i3, some basic data about its driving requirements, motor performance and topology layout have to be obtained (compare Fig. 7). The requirement for a maximum speed of the city car is $150 \mathrm{~km} / \mathrm{h}$; the vehicle mass is $1270 \mathrm{~kg}$. $75 \mathrm{~kW}$ of nominal power is supplied by a single motor at $150 \mathrm{Nm}$ and $47751 / \mathrm{min}$. The peak power of $125 \mathrm{~kW}$ results from a maximum torque of $250 \mathrm{Nm}$, while the maximum electric motor speed is 11,400 $1 / \mathrm{min}$. The motor data are in the method saved as M3. The topology is a two-stage, one-speed layout, where the first stage is a pure spur gear, while the second one is a spur gear differential. Both stages have gear ratios of approximately 3 , giving a total gear ratio of 9.67 .

To synthesize possible topology solutions for the BMW i3, a set of weights has to be specified for the criteria. To minimize subjective influences, the weights were determined by a survey conducted in the powertrain department of the Institute for Automotive Engineering (ika) of the RWTH Aachen University. Participants were asked to rate the different evaluation parameters described in the previous chapter for different vehicle types within the survey. The results for a normal passenger car are presented in Fig. 8. In general, every distribution may be chosen-specifically to the application. The polygon plot shows that costs $K$ were emphasized for the i3 by the survey participants. Mass, efficiency complexity and bearing speed were rated as successively less important.

The synthesis equipped with the weight factors from the survey produces six transmission topologies, which are theoretically feasible for the BMW i3. They are depicted in Fig. 9. The topology ranked number one resembles the real topology. A reason for this is the low number of stages which is beneficial to all synthesis criteria. Further advantages are the superior efficiency and simplicity of the spur gears. The stage gear ratios only differ by a maximum of

\begin{tabular}{lllll} 
BMW i3 & & & \\
\hline$v_{\max }[\mathrm{km} / \mathrm{h}]$ & 150 & & \\
$m_{\text {veh }}[\mathrm{kg}]$ & 1,270 & & \\
$M_{N}[\mathrm{Nm}]$ & 150 & & 今 & \\
$M_{\max }[\mathrm{Nm}]$ & 250 & $\mathrm{M} 3$ & \\
$n_{N}[1 / \mathrm{min}]$ & 4,775 & & \\
$n_{\max }[1 / \mathrm{min}]$ & 11,400 & & \\
$P_{N}[\mathrm{~kW}]$ & 75 & & \\
$P_{\max }[\mathrm{kW}]$ & 125 & &
\end{tabular}

Fig. 7 Vehicle and transmission data of BMW i3 (cf. [3] and own evaluation of transmission) ( $v_{\max }:$ maximum vehicle velocity; $m_{\mathrm{veh}}$ : vehicle mass; $M / n / P_{\mathrm{N}}$ : nominal torque/speed/power of e-machine; $M / n / P_{\max }:$ maximum torque/speed/power e-machine) 


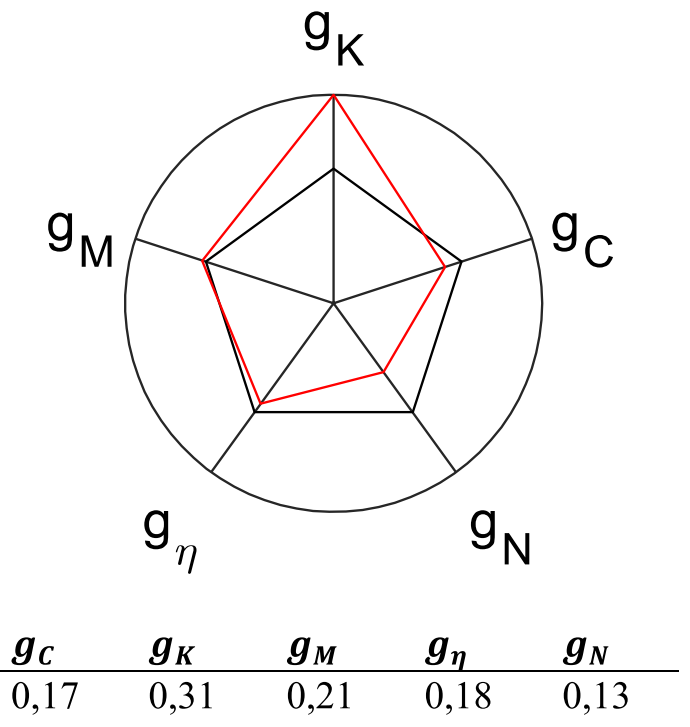

Fig. 8 Synthesis weight factors passenger vehicle taken from survey results ( $K$ : Costs; $C$ : Complexity; $N$ : Bearing speed; $\eta$ : Efficiency; $M$ : Mass)

$7.9 \%$ between real transmission and the best-rated topology of the synthesis. The rest of the synthesized topologies represent various possible combinations of spur and planetary gears that can provide the required total gear ratio.

Before running the design process, the weights for the combination step need to be set. Those were also determined by the already mentioned survey and are shown in Fig. 10. The weights are distributed rather evenly, with a slight emphasis on mass and less emphasis on service life.
The initial design and evolutionary combination are now applied to all topology variants from Fig. 9. The final results contain 250 geometry variants for every topology, which are ranked $1-250$ by the final evaluation. First, the geometry variants are regarded by their combination criteria in Fig. 11. In the mass-efficiency diagram, six point clouds emerge, which represent the six topology variants. Dark blue corresponds to variant 1 , while the second cloud at the Pareto front in the top left corner is variant number 2 . Thus, the synthesis has identified the optimal topologies for mass and efficiency as numbers 1 and 2 in the topology ranking. Service life and safeties are more varying for each topology; no clear clouds emerge here. In this case, a design variant with near-optimal service life and safety for every topology can be found because their values are widespread. In general, the values for efficiency, safety and service life resemble values seen in current applications. Efficiencies (gear meshing only) range between 0.97 and 0.995 , service life is generally around or above the specified optimum of 250,000 km [21] and safeties above 1.

Finally, the dimensions of the generated designs are compared to the real dimensions of the topology. Wheel width, diameter, axle distance, number of teeth and module are regarded in Fig. 12. The variety of the 250 designs generated for topology number one are shown in boxplots. As the figure shows, the generated designs fall around the real dimensions of the transmission of the BMW i3. It is evident that the wheel diameters and widths of the generated designs always enclose the parameters of the real transmission marked by a blue X. Only the generated diameters for the driven side of stage one are slightly bigger than the reference. This is due to the greater gear ratio

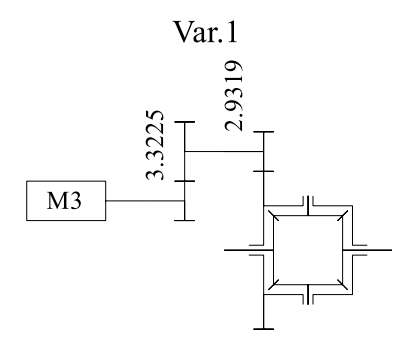

Var.2

Var.3

Var.4
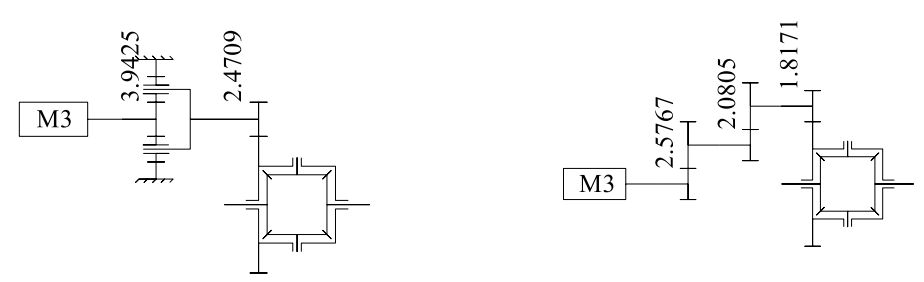

Var.5

Var.6
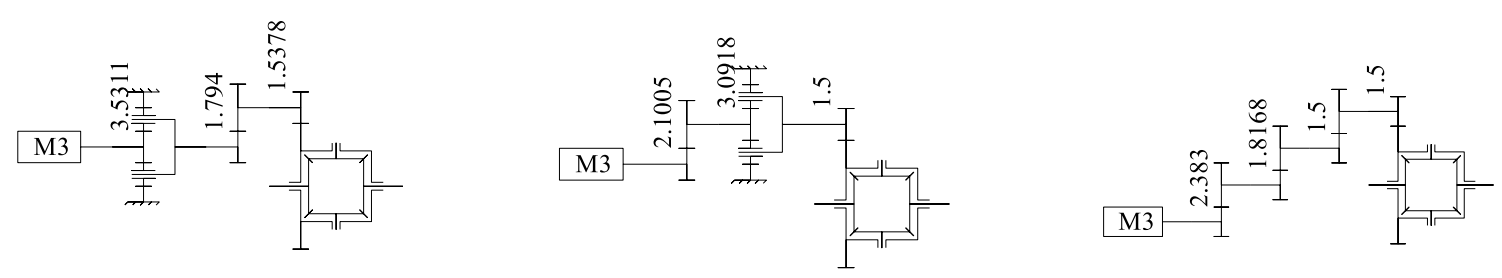

Fig. 9 Ranking of synthesized topologies for BMW i3 


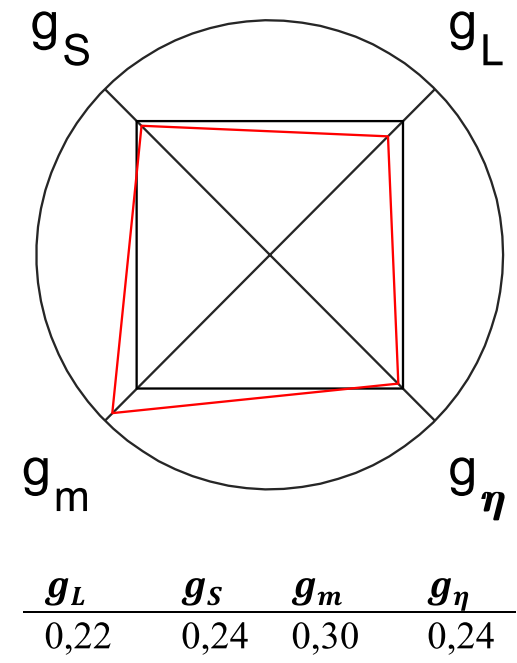

Fig. 10 Combination weights passenger vehicle taken from the survey results ( $S$ : Safety; $L$ : Service life; $\eta$ : Efficiency; $m$ : Mass)

of stage one in the synthesized topology compared to the real one. To accommodate the greater gear ratio with a comparable size of the drive wheel, the driven wheel needs to be bigger. To summarize, the dimensions generated by the method are comparable to the real dimensions of the reference transmission.

By the presented results of the application of the transmission synthesis for the BMW i3, it can be stated that the developed method is validated. The results are close to the original design. A complete overlapping of the values can not be reached as only roughly designed gears are considered, and always changes are made in the further design process, e.g., within the fine design of gears. Analytically designed transmissions tend to be slightly bigger regarding their axle distance than the real built transmissions in vehicles [21]. That underlines the validity of the method reached results shown in Fig. 12.

\subsection{Application for a 40-ton truck}

To present the broad field of possible applications of the presented methods in this section, the synthesis approach is applied to achieve an overview of the solution space for a 40-ton truck axle application. The presented research was conducted in the context of the Concept $\mathrm{ELV}^{2}$ project [15]. The project context defines the motors and general topology concept. For electric trucks, no status quo, but many different powertrain concepts exist up to this point [26, 28]. As before, the driving requirements and motor data for the application are obtained first (compare Table 7). The required maximum speed of $100 \mathrm{~km} / \mathrm{h}$ facilitates swift overtaking manoeuvres of the 40-ton truck ( 9.42 tons empty weight). Power is supplied by two electric motors, with M1 being the main motor and M2 supplying a boost functionality. Their main difference is within the nominal and maximum torques, where $\mathrm{M} 1$ provides $530 \mathrm{Nm}$, which is twice the output of M2 $(265 \mathrm{Nm})$. Their nominal speeds of $4500 \mathrm{1} /$ min are identical, while maximum speeds are similar. The power figures mirror the torque outputs.

The already introduced survey for the weight factors of the BMW i3 also gathered data for a truck application. The results are shown in Fig. 13. Most prioritized were efficiency, costs and bearing speeds, with mass and complexity rated least important.

The synthesis process is initialised with the weights from Fig. 13. As the application concerns a truck axle, the synthesis is instructed to synthesize topologies, where the output of both motors is transferred to a single differential. Also, a maximum number of five stages is defined for this application. The synthesis generates 378 different topologies with its holistic combination approach of the possible elements and allowed number of stages (see Sect. 3.1). The top 12, rated by the method, are depicted in Fig. 14. There emerges no trend of predominantly spur or planetary gear topologies in the top 12, rather a competing mixture of all gear types.
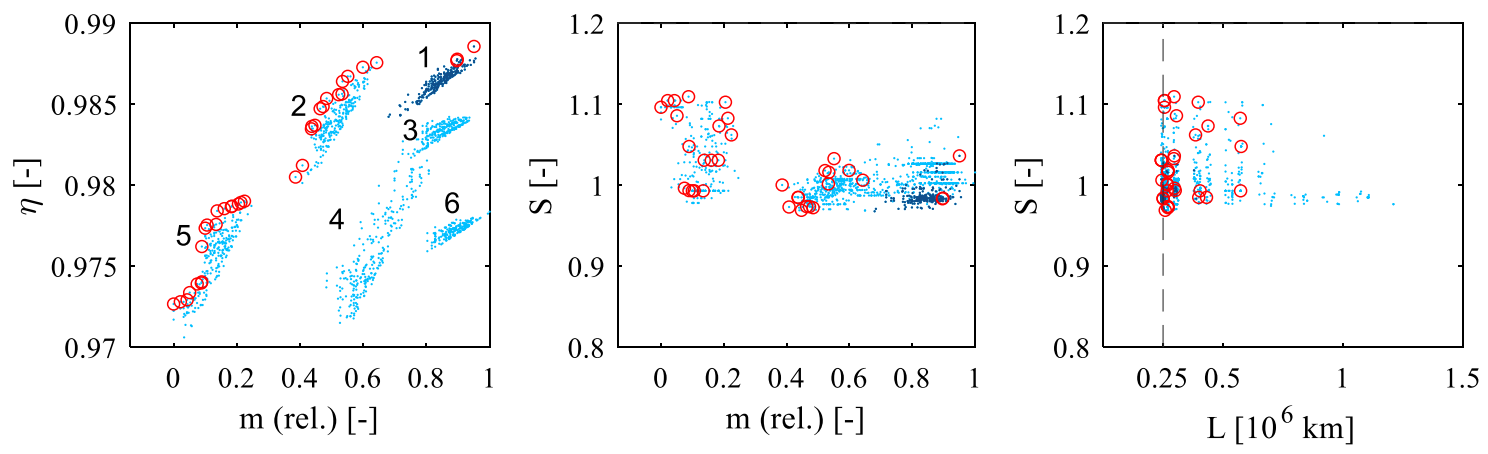

Fig. 11 Combination criteria of geometry variants for BMW i3Numbers 1-6: Transmission topologies from Fig. 9; light blue: one variant within the transmission concepts; dark blue: BMW i3 trans- mission topology; red circles: Pareto optimum $m / \eta$ I ( $\eta$ : Efficiency; $m$ : Mass; $S$ : Safety; $L$ : Service life) 

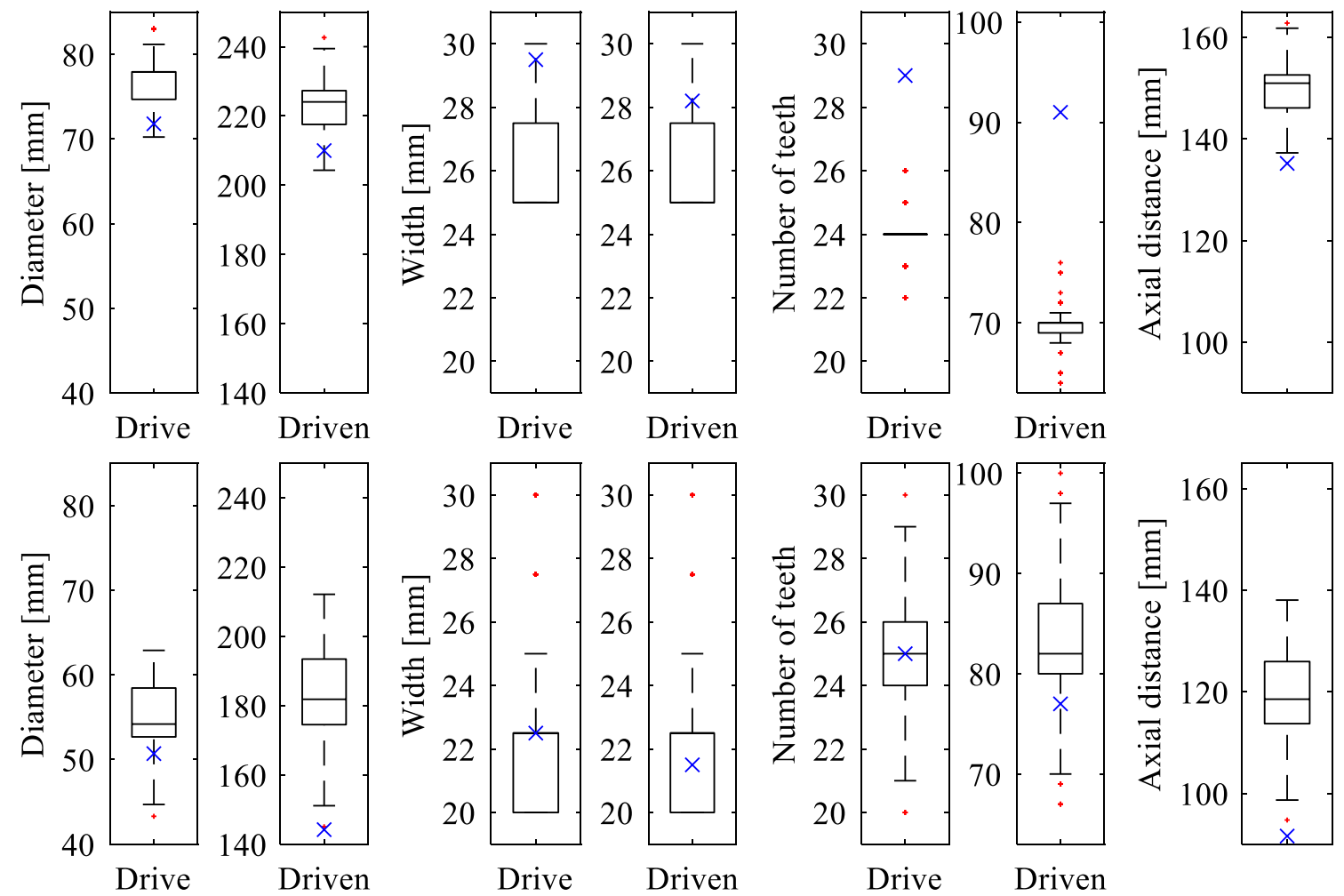

Driven
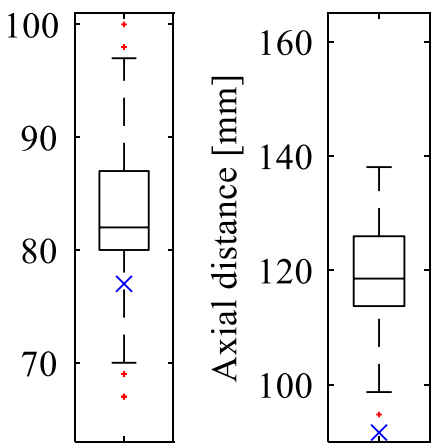

Fig. 12 Original transmission in BMW i3 (blue X) vs ranges of dimensions of method results (upper part: first gear step; lower part: second gear step)—red dots are single outliers

Table 7 Vehicle and electric motor data of 40-ton truck in Concept ELV ${ }^{2}$ project

\begin{tabular}{lcr}
\hline 40 -ton truck & & \\
\hline$v_{\max }[\mathrm{km} / \mathrm{h}]$ & 100 & $9420-40,000$ \\
$m_{\text {Fzg }}[\mathrm{kg}]$ & $M 1$ & $M 2$ \\
\hline & 530 & 265 \\
$M_{\mathrm{N}}[\mathrm{Nm}]$ & 700 & 350 \\
$M_{\max }[\mathrm{Nm}]$ & 4500 & 4500 \\
$n_{\mathrm{N}}[1 / \mathrm{min}]$ & 10,000 & 11,000 \\
$n_{\max }[1 / \mathrm{min}]$ & 250 & 125 \\
$P_{\mathrm{N}}[\mathrm{kW}]$ & 330 & 165 \\
$P_{\max }[\mathrm{kW}]$ & & \\
\hline
\end{tabular}

$v_{\max }$ maximum vehicle velocity; $m_{v e h}$ vehicle mass; $M / n / P_{N}$ nominal torque/speed/power of e-machine; $M / n / P_{\max }$ maximum torque/speed/power e-machine

Whether a more planetary-based topology is rated better than a spur-based one depends on how well it can play to its strengths, especially considering its gear ratio distribution. Spur gears are generally better suited for the efficiency criterion, and planetary gears have an advantage in cost and bearing speed criteria.

Before the initial design and evolutionary combination, the weights for the fitness score have also been determined by the survey for the 40-ton truck. The results are shown in
Fig. 15. Efficiency, service life and safety have been prioritized to the disadvantage of mass.

All 378 topologies are automatically designed and rated by the method. The result tables contain the top 250 geometry variants of every topology. In sum, overall topologies and variants, more than $10^{9}$ possible transmission concepts were generated and evaluated. Dark blue is the topology ranked number one by the synthesis. It represents a compromise between all four combination criteria. In general, 


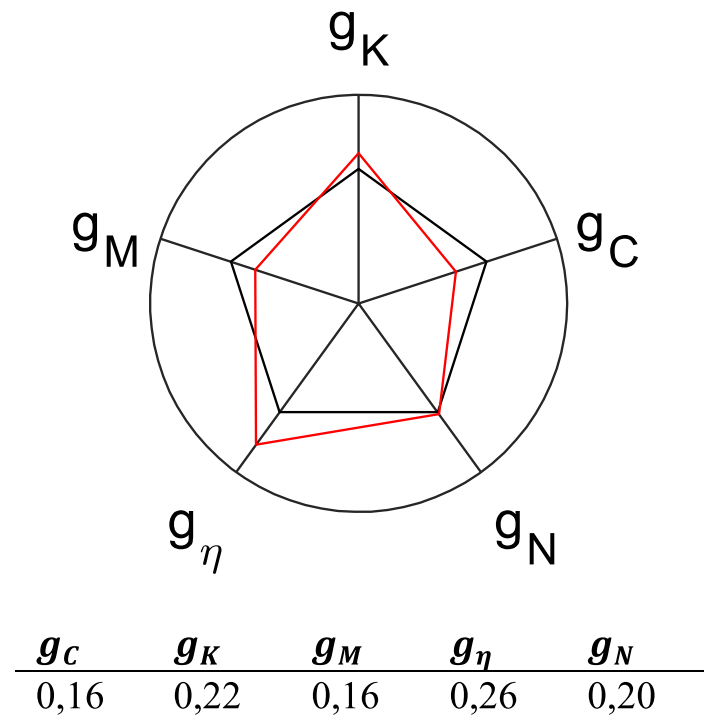

Fig. 13 Synthesis weight factors for a 40-ton truck taken from the survey results $(K$ : Costs; $C$ : Complexity; $N$ : Bearing speed; $\eta$ : Efficiency; $M$ : Mass)

efficiencies, service life, and safeties are conform to state of the art-with service life values for trucks ranging from 0.4 to 1.2 million kilometers [21]. The results in Fig. 16 present the solution space of the 378 solutions for a 40 ton truck with two electric motors.

For every topology, 250 variants are plotted-which makes roughly 90.000 . Not for all of the topology concepts, a sufficient gear design is found. The next step in the development process would be to choose one or a few favourable topologies and start the gear design for those concepts
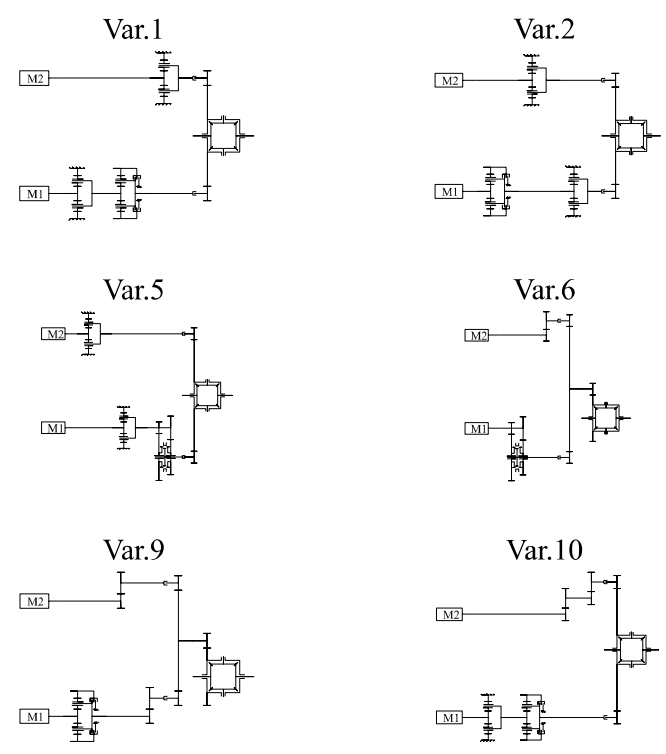

Fig. 14 Exemplary top 12 of 378 synthesized topologies for a 40-ton truck within smaller ranges with a more detailed step size. A detailed design of all possible topologies is theoretically possible but would dramatically increase calculation time and memory occupation. With the results of this, the first draft of a bearing-shaft system can be designed.

\section{Discussion}

The presented synthesis approach is capable of designing transmission concepts for various vehicles. Here, the method is applied to a BMW i3 and a 40-ton truck to show its applicability. The results generated for the passenger car enclose the actual built transmission's specification so that the method can be seen as validated.

The procedure, starting from the motor and vehicle data up to an initial design of the gears, can be very beneficial for engineers in an early transmission development stage as they receive many solution proposals at this early stage. Furthermore, the integrated two-stage evaluation process is an advantage as the weight factors of the criteria can be freely changed so that engineers can adapt the method to variable use-case specific requirement profiles. Focusing on the simpler transmissions in fully electric cars compared to conventional and hybrid vehicles opens up the possibility to raise the level of detail in gearing design. That enables the presented process to use calculated data and a wide range of options to reach an optimal solution base for further development steps. The huge number of possible solutions underlines the possibilities that this method offers to the transmission developers.
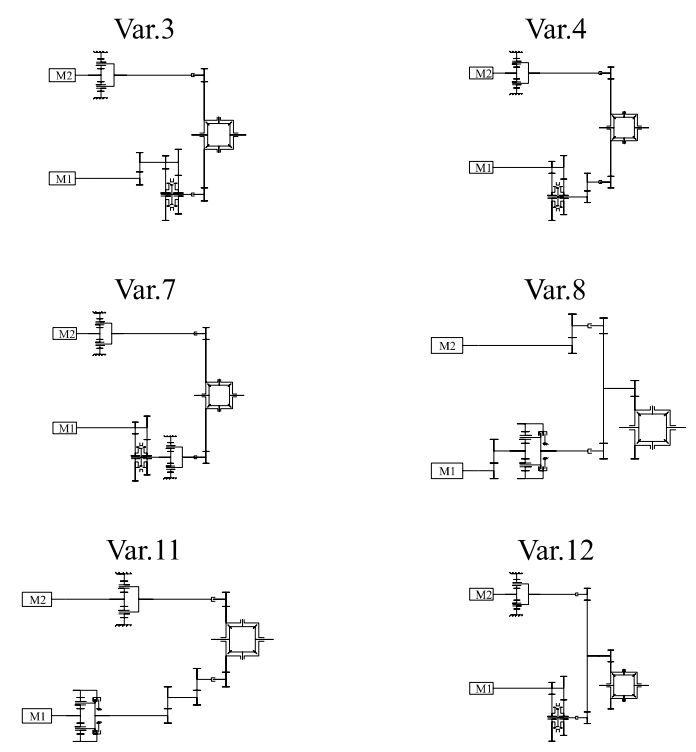


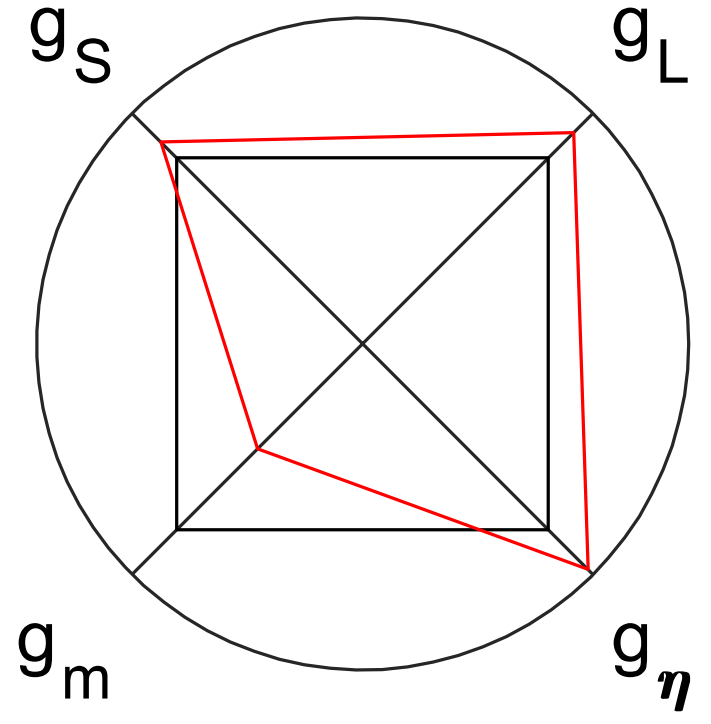

\begin{tabular}{llll}
$\boldsymbol{g}_{\boldsymbol{L}}$ & $\boldsymbol{g}_{\boldsymbol{s}}$ & $\boldsymbol{g}_{\boldsymbol{m}}$ & $\boldsymbol{g}_{\boldsymbol{\eta}}$ \\
\hline 0,28 & 0,27 & 0,14 & 0,31
\end{tabular}

Fig. 15 Combination weight factors for a 40-ton truck taken from survey results ( $S$ : Safety; $L$ : Service life; $\eta$ : Efficiency; $m$ : Mass)

Users only need information on the vehicle and motor data and can start the process to synthesize transmission concepts. It is possible to choose electric motors from an integrated database, or own motors can be implemented by the user. This makes the method agile for many use cases.

Compared to earlier approaches presented in chapter two, this method covers a more detailed synthesis of the transmission-first of the topology itself and second by the rough design and optimization of the gear data. The possible complexity of the synthesized transmissions is manageable due to excluding special and combined planetary gears; thus, many possible geometries of the simple planetary gears are created.
Furthermore, the total gear ratio is not defined beforehand but is calculated based on boundary conditions within the synthesis. It is calculated based on vehicle properties and properties of the e-machine like highest torque, maximum speed and most efficient point. Also, the ratios of the single gear steps are distributed based on an internal evaluation. The method may result in significant improvement of the development process of transmissions for electric vehicles. The fast processing of synthesizing topologies creates a huge number of possible geometries in the rough gear design. It evaluates many possible solutions (car: six topologies I truck: 378 topologies I with $\sim 10^{6}$ options per stage) within a comparatively short time is a further advantage. The calculating time on the RWTH Aachen Universities' computing cluster took $39 \mathrm{~h}$ for the cars' topologies and $260 \mathrm{~h}$ for the trucks' topologies.

Especially in the truck segment, the method supports the selection of a feasible transmission topology as no state of the art topology exists, and the development of electric trucks is still young and very dynamic. Likewise, the market of electric cars will grow-due to a change of mind in the public, government regulations and incentives. With this fast-growing market, the need for a quick, sufficient and valid method to investigate possible transmission concepts is becoming more and more relevant. By this, the chance to oversee a possible good fitting solution decreases as the method is holistically in the given boundary conditions. The speed of developing a new transmission increases as possible iterations due to changed topologies in a later stage may be dismissed.

\section{Conclusion and outlook}

This methodology provides the user with a structured and exhaustive overview of possible transmission variants at the start of development. The automated character of the method allows evaluation of previously unfeasible numbers of variants and reduces time lost to iteration. The data gathered
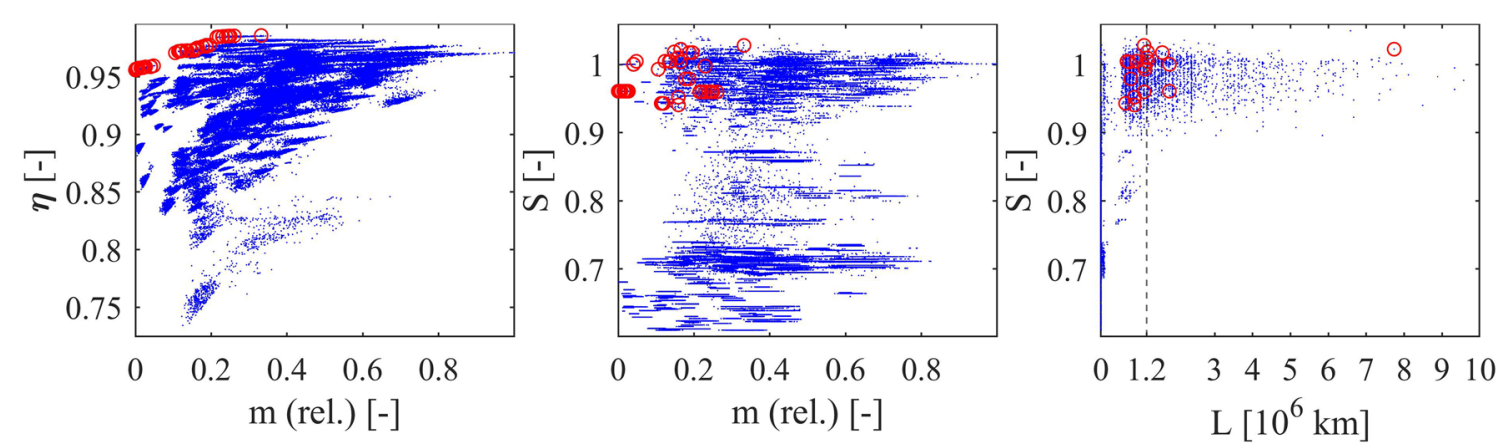

Fig. 16 Combination criteria of geometry variants for a 40-ton truck ( $\eta$ : Efficiency; $m$ : Mass; $S$ : Safety; $L$ : Service life) 
from this methodology can then be used as a basis for further in-detail development of the EV transmission.

Additional applications of the presented method are the variation of the vehicle and electric motor combination. For example, the motor of Porsche Taycan could be set as input for a car like the VW ID3 to evaluate how the transmission would change or to detect equal transmission parts. In a future application, the synthesis will be used to evaluate the impact of high-speed motor concepts. For this purpose, the validated BMW i3 will be combined with a high-speed electric machine. The results of the base run, presented in this paper, and those with the high-speed concept can be compared to analyze the impacts of a motor for the transmission design and topology. This again shows the widespread field of application of this method in research (impact of different machines in vehicles) and development (find the best fitting transmission for a defined use-case).

The method can be extended with more complex gear structures as, e.g., step planets or Ravigneaux sets in further steps. Also, an automatic iteration loop could be integrated to optimize the best solutions of the previous run. The method will show its usability within the growing electric cars market and thus more transmissions for these vehicles. As all settings may be freely chosen, the method aims to support the development of transmission for a huge number of use-cases.

Acknowledgements The authors thank Univ. Prof. Dr.-Ing. Lutz Eckstein for supporting and supervising this research.

Funding Open Access funding enabled and organized by Projekt DEAL. The presented method is developed within project Concept $E L V^{2}$ (grant number: 01MY17002B), founded by Federal Ministry for Economic Affairs and Energy (BMWi). Simulations were performed with computing resources granted by RWTH Aachen University under project thes 0948 and thes 0960 .

\section{Declarations}

Conflict of interest The authors declare that they have no conflict of interest.

Ethics approval Not applicable.

Consent to participate Not applicable.

Consent for publication Not applicable.

Open Access This article is licensed under a Creative Commons Attribution 4.0 International License, which permits use, sharing, adaptation, distribution and reproduction in any medium or format, as long as you give appropriate credit to the original author(s) and the source, provide a link to the Creative Commons licence, and indicate if changes were made. The images or other third party material in this article are included in the article's Creative Commons licence, unless indicated otherwise in a credit line to the material. If material is not included in the article's Creative Commons licence and your intended use is not permitted by statutory regulation or exceeds the permitted use, you will need to obtain permission directly from the copyright holder. To view a copy of this licence, visit http://creativecommons.org/licenses/by/4.0/.

\section{References}

1. Audi, A. G.: Audi e-tron: Technincal Data (2020)

2. BMW Group: BMW Media Information: Specifications. The new BMW i3 (2017)

3. BMW Group: Technical Specifications BMW i3. https://www. press.bmwgroup.com/global/article/attachment/T0284828EN/ 415571. (2018) Accessed 19 August 2021

4. Breiing, A., Knosala, R.: Bewerten Technischer Systeme: Theoretische und methodische Grundlagen bewertungstechnischer Entscheidungshilfen. Springer, Berlin Heidelberg (1997)

5. Daimler Truck, A. G.: A new truck for a new era: Mercedes-Benz eActros celebrates its world premiere. https://media.daimler.com/ marsMediaSite/en/instance/ko.xhtml?oid $=50352780$. Accessed 19 August 2021

6. European Parliament and Council.: Regulation (EC) No 715/2007 of the European Parliament and of the Council. (2007). https:// eur-lex.europa.eu/legal-content/EN/TXT/PDF/?uri=OJ:L:2007: 171:FULL\&from=EN. Accessed 16 Dec 2021

7. European Parliament and Council.: Regulation (EC) No 595/2009 of the European Parliament and of the Council. (2009). https:// eur-lex.europa.eu/legal-content/EN/TXT/PDF/?uri=OJ:L:2009: 188:FULL\&from=EN. Accessed 16 Dec 2021

8. European Parliament and Council.: Regulation (EU) 2018/956of the European Parliament and of the Council. (2018). https://eurlex.europa.eu/legal-content/EN/TXT/PDF/?uri=CELEX:32018 R0956\&from=EN. Accessed 16 Dec 2021

9. Hirzel, C.: Ein Beitrag zur Synthese und Analyse elektrifizierter Fahrzeuggetriebestrukturen aus einer Kombination von Stirnrad- und Planeten-getrieben mit Fokus auf die systematische Rea-lisierung einer hinreichenden Gangverteilung. Dissertation, Otto-von-Guericke Universität (2018)

10. Institute for Automotive Engineering Concept ELV ${ }^{2}$. https:// www.ika.rwth-aachen.de/en/research/projects/energy-and-drive train-management/2816-concept-elv2-en.html. (2021) Accessed 1 June 2021

11. International Organization for Standardization.: ISO 21771:2007(E): Gears - Cylindrical involute gears and gear pairs - Concepts and geometry. Geneva, Switzerland (2007)

12. International Organization for Standardization.: ISO 6336:2019(E): Calculation of load capacity of spur and helical gears. Geneva, Switzerland (2019)

13. Kieninger, D., Hemsen, J., Köller, S., Uerlich, R.: Automatisierte Auslegung und Optimierung von Getrieben für Elektrofahrzeuge. MTZ Motortech Z 80, 94-99 (2019). https://doi.org/10.1007/ s35146-019-0129-8

14. Klocke, F., Brecher, C.: Zahnrad- und Getriebetechnik. Carl Hanser Verlag GmbH \& Co, KG, München (2016)

15. Köller, S., Uerlich, R., Westphal, C., Franck, M.: Auslegung einer elektrischen Antriebsachse für einen schweren Lkw. ATZheavy Duty (2021). https://doi.org/10.1007/s35746-021-0423-5

16. Kurth, F.: Efficiency Determination and Synthesis of ComplexCompound Planetary Gear Transmissions. Technical University of Munich (TUM), ISBN: 978-3843907897 (2012)

17. Li, X.: Systematische Synthese mehrgängiger Planetengetriebe. Dissertation, RWTH Aachen (1993)

18. Li, L., Chen, H., Küçükay, F.: Systematic synthesis of dedicated hybrid transmission. Autom. Innov. 2, 231-239 (2019). https:// doi.org/10.1007/s42154-019-00071-3 
19. Lilienkamp, A., Kienscherf, P.A., Schroer, K., Gierking, M.: Analyse zukünftiger Elektrofahrzeugnutzung auf Basis von AppDaten. et - Energiewirtschaftliche Tagesfragen 70(11), 53-55 (2020). https://www.ewi.uni-koeln.de/cms/wp-content/uploads/ 2020/11/201130_et-Artikel_Analyse-zukuenftiger-Elektrofah rzeugnutzung-auf-Basis-von-App-Daten.pdf. Accessed 16 Dec 2021

20. MathWorks.: MATLAB Documentation: ga - find minimum of function using genetic algorithm (2020). https://www.mathworks. com/help/gads/ga.html. Accessed 16 Dec 2021

21. Naunheimer, H., Bertsche, B., Ryborz, J., Novak, W., Fietkau, P., Gretzinger, Y.: Fahrzeuggetriebe: Grundlagen, Auswahl, Auslegung und Konstruktion, 3rd edn. Springer Vieweg, Berlin, Germany (2019)

22. Ohlendorf, H.: Verlustleistung und Erwärmung von Stirnrädern: Einfluss von Schmierung, Zahnform, Bearbeitung, Werkstoff, Belastung und Umfangsgeschwindigkeit auf den Verlustgrad und die Erwärmung von Stirnrädern mit Geradverzahnung. Dissertation, Technische Universität München (1958)

23. Porsche, A. G.: Taycan: Two-speed transmission on the rear axle (2019a) https://presse.porsche.de/prod/presse_pag/PressResou rces.nsf/Content?ReadForm\&languageversionid=1039986\&hl= modelle-taycan-taycan_turbo_s. Accessed 19 August 2021

24. Porsche, A. G.: The powertrain: Pure performance: Porsche Taycan (2019b)

25. Ruoff, S., Kalt, F., Bause, K., Albers, A.: Methode zur automatisierten Topologiesynthese und Bewertung hybrider Antriebsstränge.
In: Krause D, Paetzold, Kristin, Wartzack, Sandro (eds) DFX 2019: Proceedings of the 30th Symposium Design for X, 18-19 September 2019, Jesteburg, Germany. The Design Society (2019)

26. Silvas, E., Hofman, T., Serebrenik, A., Steinbuch, M.: Functional and cost-based automatic generator for hybrid vehicles topologies. IEEE/ASME Trans. Mechatron. 20, 1561-1572 (2015). https:// doi.org/10.1109/TMECH.2015.2405473

27. United Nations (2015) Paris Agreement, United Nations Framework Convention on Climate Change

28. Verbruggen, F.J.R., Silvas, E., Hofman, T.: Electric powertrain topology analysis and design for heavy-duty trucks. Energies 13, 2434 (2020). https://doi.org/10.3390/en13102434

29. Verein Deutscher Ingenieure.: VDI 2157: planetary gear drives. Berlin (2012)

30. Volkswagen, A G.: In brief: The all-rounder-the 1-speed gearbox. https://www.volkswagenag.com/en/news/2020/02/in-briefthe-all-rounder-the-1-speed-gearbox.html\#. (2020) Accessed 19 August 2021

31. Wirth, C., Ernstorfer, M., Fuchs, A.: Das Getriebesyntheseprogramm der ZG GmbH (2014)

Publisher's Note Springer Nature remains neutral with regard to jurisdictional claims in published maps and institutional affiliations. 